\title{
A Case of Bilateral Thalamic Infarct Misdiagnosed as Conversion Disorder
}

\author{
Konversiyon Tanısı Alan Bilateral Talamik Enfarkt Vakası
}

\author{
Burak Subaşı
}

Elazığ Education and Research Hospital, Psychiatry Unit, Elazığ, Turkey

\begin{abstract}
Introduction: Thalamic infarcts are rarely seen clinical situations. The most important causes are small vessel diseases and lacunar infarctions, arterio-arterial embolisms due to large artery diseases, emboli originating from the heart, and migrainous strokes. Patients might be misdiagnosed because of presenting similar symptoms that are detected in psychiatric disorders; this may lead to a delay in proper treatment. .
\end{abstract}

Case Report: A 73-year-old female patient presented to the emergency service with dizziness, somnolence, and unwillingness to talk and was initially diagnosed with conversion disorder, consulting with the psychiatry unit. In the neurological examination, limited cooperation, bilateral pupillary expansion, and vertical gaze palsy were observed. In brain magnetic resonance imaging (MRI), a lesion flashing in the diffusion sequences with glowing ADC sequences and acute ischemic lesions compatible with bilateral paramedian thalamic vessel territory were detected; antiplatelet and low-molecular-weight heparin therapy was started. During follow-up, short-term and distant long-term memory problems emerged. At the end of the 1-month followup, gaze paresis and sleepiness partially improved. However, the memory problems and slowness of the overall behaviors did not change prominently.

Conclusion: In cases with bilateral paramedian thalamic artery obstruction, persistent amnesia; perseveration; deficits in naming, speech intensity, and fluency; attention; slowness of the overall behaviors; somnolence; emotional changes; decreased motivation; and memory problems are common clinical features. Symptoms may completely improve in a minority of patients.

Keywords: Bilateral thalamic infarct, conversion disorder, memory deficit

Received: 18.03.2013 Accepted: 19.03.2013

\section{ÖZET}

Giriş: Talamik infarktlar nadir görülen klinik durumlardır. En önemli nedenler küçük damar hastalığı ve buna bağlı laküner enfarktlar, arterden artere emboli olan büyük damar hastalıkları, kalp kaynaklı emboli ve migrenöz inmelerdir. Hastalar psikiyatrik bozukluklarda görülen belirtilere benzer bulgular gösterdikleri için yanlışlıkla psikiyatrik hastalık tanısı konulabilir, bu durum uygun tedaviyi geciktirebilir.

Olgu Sunumu: Acil servise başdönmesi, uykuya meyil, konuşmak istememe nedeniyle yakınları tarafından getirilen 73 yaşındaki kadın hasta konversiyon bozukluğu öntanısı ile psikiyatri bölümüne konsülte edilen hastanın yapılan nörolojik muayenesinde kooperasyonu kısıtlı olmakla beraber iki yanlı pupillerde genişleme ve vertikal bakış parezisi gözlendi. Beyin manyetik rezonans görüntülemelerinde (MRG), difüzyon sekanslarda parlayan ADC sekansta sönen akut iskemi ile uyumlu bilateral paramedian talamik arter alanında lezyonları tespit edilen hastaya antiagregan ve düşük moleküler ağırlıklı heparin başlandı. Hastanın izleminde yakın ve uzak bellekle ilgili problemler ortaya çıktı. Bir aylık izleminde hastanın yukarı bakış parezisinde ve uyku halinde kısmi düzelme gözlendi. Ancak bellek problemleri ve davranışlarındaki yavaşlamada belirgin bir değişiklik gözlenmedi.

Sonuç: Bilateral paramedian talamik arter tıkanmaları olan vakalarda ısrarlı amnezi, perseverasyon, isimlendirmede, konuşma yoğunluğu ve akıcıı̆ğında azalma, dikkat bozukluğu, hareketlerde yavaşlama, uyku hali, duygusal değişiklikler, motivasyonda azalma ve bellek problemleri sık görülen klinik tablolardır. Hastaların az bir kısmında belirtiler tama yakın düzelmektedir.

Anahtar Kelimeler: Bilateral talamik infarkt, konversiyon bozukluğu, bellek bozukluğu

Geliş Tarihi: 18.03.2013 Kabul Tarihi: 19.03.2013 


\section{Giriş}

Talamik infarktlar nadir görülen klinik durumlar olup; vertebrobaziller infarktların \%11'ini oluştururlar. Talamik infarkt vakaları beyinde etkilenen bölgeye bağlı olarak supranükleer palsy, somnolans, nöropsikolojik bozukluklar ve hafıza bozukluğu gibi çok değişik klinik tablolarla karşımıza çıkabilirler (1, 2).

En önemli nedenler küçük damar hastalığı ve buna bağlı laküner enfarktlar, arterden artere emboli olan büyük damar hastalıkları, kalp kaynaklı emboli ve migrenöz inmeler olmakla birlikte $(3,4)$ bölgeyi besleyen; sıklıkla da paramedian/talamogenikulat arterlerin anatomik bir varyasyonuna bağlı olarak tek olması sonucunda da oluşabilir. Yapılan bir araştırmada 7 yıl içinde inme nedeniyle başvuran hastaların \%0,6'sında bilateral talamik enfarkt gözlenmiştir (5). Bu hastaların çoğunda görülen klinik bulgular: vertikal bakış parezisi, uyanıklık periyodunda azalma, duygu değişiklikleri, motivasyonda azalma ve bellekle ilgili problemlerdir (6). Bu vaka sunumunda hastanemiz acil servisine nörolojik belirtilerle getirilen ancak öyküsünde konversiyon bozukluğu ve depresyon olması nedeniyle psikiyatri bölümüne konversiyon bozukluğu öntanısı ile danışılan bir hasta sunulmuştur.

\section{Olgu Sunumu}

Acil servise başdönmesi, uykuya meyil, konuşmak istememe nedeniyle yakınları tarafından getirilen 73 yaşındaki kadın hasta konversiyon bozukluğu öntanısı ile psikiyatri bölümüne konsülte edilmişti. Hastanın özgeçmişinde 20 yıllık hipertansiyon ve diyabet öyküsü olup; Ramipril 5 mg/gün, Amlodipin 10 mg/gün ve Metformin 2×500 mg/gün tedavilerini alıyordu. Hasta 40 yıldır tekrarlayan depresif belirtiler ve konversif bayılmalar nedeniyle ara ara ilaç tedavileri almıştı ve başvuru esnasında bir antidepresan ajan olan sertralin 50 mg/gün tedavisini kullanıyordu. Eşi durumunun iyi olduğunu, önceki bayılmalarının şu andaki durumuna benzemediğini belirtiyordu. Hasta somnole (sesli ve ağrılı uyaranlara kısa süreliğine uyandığında tek kelime konuşup tekrar uykuya daldığı için) olduğundan ruhsal muayene tam olarak yapılamadı. Destekle bir miktar yürüyebildi. Yapılan nörolojik muayenede kooperasyonu kısıtlı olmakla beraber iki yanlı pupillerde genişleme ve vertikal bakış parezisi gözlendi. Tüm ekstremiteler hareketli, derin tendon refleksleri normoaktif ve taban cildi refleksleri iki yanlı fleksör olarak alınıyordu. Tansiyon 170/100mmHg, nabız 70/dk idi. Organik patoloji ön planda düşünülen hastanın çekilen elektroensefalografide herhangi bir epileptik deşarj saptanmadı ve normal sınırlarda olarak rapor edildi. Beyin manyetik rezonans görüntülemelerinde (MRG), difüzyon sekanslarda parlayan ADC sekansta sönen akut iskemi ile uyumlu bilateral paramedian talamik arter alanında lezyonları tespit edilen hasta nöroloji kliniğine yatırıldı (Şekil 1). Tedavi olarak hastaya antiagregan ve düşük moleküler ağırııklı heparin başlandı. İstenen rutin kan tetkiklerinde açıı kan şekeri 175 mg/dl olarak ölçüldü. Tam kan sayımı, karaciğer ve böbrek fonksiyon testleri, serum elektrolit düzeylerinde herhangi bir anormallik saptanmadı. İstenen pıhtılaşma bozuklukları panelinde herhangi bir patoloji saptanmadı. Hastanın izleminde yakın ve uzak bellekle ilgili problemler ortaya çıktı. Bir aylık izleminde hastanın yukarı bakış parezisinde ve uyku halinde kısmi düzelme gözlendi. Ancak bellek problemleri ve davranışlarındaki yavaşlamada belirgin bir değişiklik gözlenmedi.

\section{Tartışma}

Paramedian talamik infarktların akut gelişen bilinç değişiklikleri, vertikal bakış kusuru ve nöropsikolojik bozukluklardan oluşan klasik üçlemesi vardır. Letarji, stupor, hipersomnolans görülebilir. Hastalar uyandırılabilir, ancak uyaran kesilince tekrar uyuklamaya başlarlar. Bilinç bozuklukları rostral mezensefalon ve intralaminar nükleusların tutulumuna bağlıdır. Sıklıkla yukarı bakış bozuklukları bulunur.

Mezensefalik retiküler formasyona dâhil olan Darkschewitsch nükleusu, medial longitudinal fasikül'ün rostral interstisyel nükleusu (riMLF), Cajal nükleusu ve posterior kommisür yapılarının vertikal bakış mekanizmasında rolleri olduğu bilinmekle birlikte, vertikal bakışın supranükleer yolları, horizontal bakış yolları kadar net tanımlanmamıştır. Medial talamik lezyonların, motor ve premotor korteksten kalkan ve mezensefalonda bulunan Cajal'ın intertisyel nükleusu ile Darkschewitsch nükleusu arasında bağlantı oluşturan kortikofugal liflerin kesilmesine neden olarak vertikal göz hareketlerini (aşağı ve yukarı) etkilediği düşünülmektedir (7). Talamus, hipokampus ve limbik sistem gibi bellek sistemleri ile fronto-paryetal bağlantıların kesişme noktasıdır. Talamik lezyonu olan hastalarda bilinç bozuklukları sık görülmekte ve düzelince nöropsikolojik anomaliler, dezoryantasyon, ilgisizlik ve apati devam edebilmektedir. Dorsomedial, santromedian parafasiküler nukleuslar bellek ve dikkatin yönlendirilmesini sağlayan sistemleri yönetir. Bilateral paramedian talamik arter tıkanmalarında ısrarlı amnezi, perseverasyon, yakın bellek bozukluğu, isimlendirmede, konuşma yoğunluğu ve akıcılığında azalma, dikkat bozukluğu, genel davranışın yavaşlaması gibi akut demansiyel tablolar görülebilir. Sağ medial talamus enfarktlarında solda vizüel ihmal, konstrüksiyonel apraksi görülebilir $(8,9)$. Literatürde nadiren tam düzelen hastalar da bildirilmiştir (10).

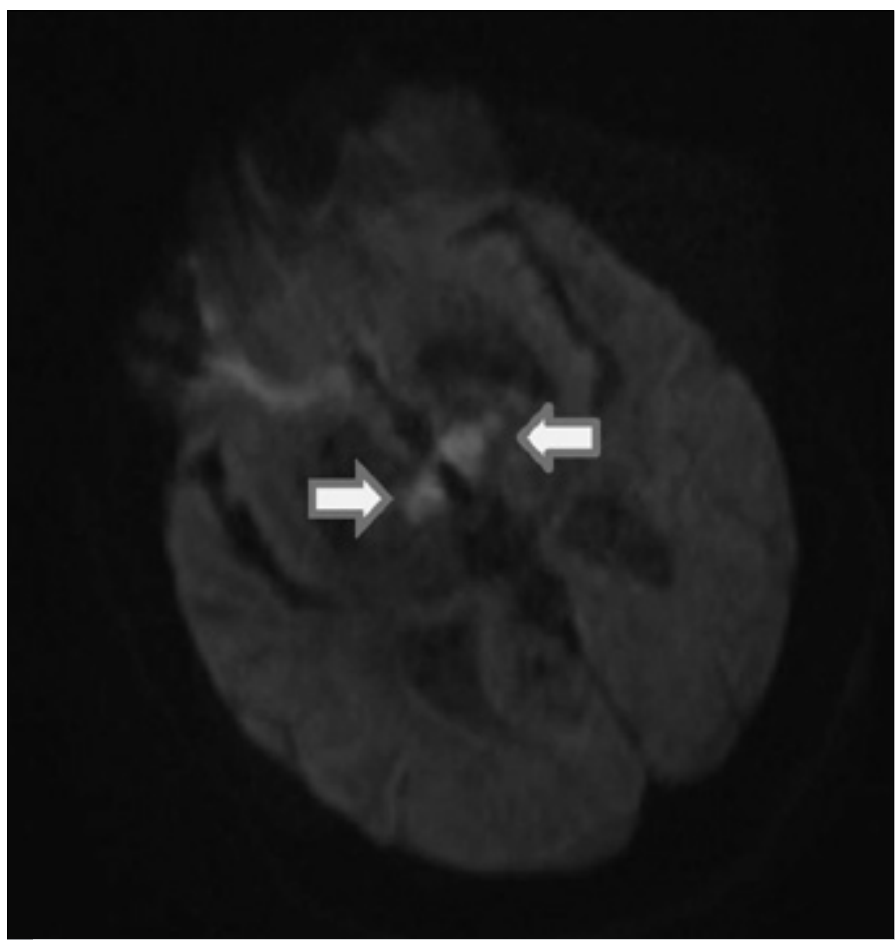

Şekil 1. Difüzyon beyin MRI' da bilateral talamik enfarkt odağı 
Sonuç olarak bu vakayı sunmaktaki amacımız psikiyatrik hastalık öyküsü olanlarda mevcut semptomları psikopatolojiye bağlayıp acilde atlamamak gerektiğini vurgulamak, acil servise ani bilinç değişikliği ile başvuran uyku hali mevcut olup lateralize bulgusu olmayan hastalarda bilateral talamik infark tanısını akla getirmek ve literatür bilgileri ışığında konuyu gözden geçirmektir.

Hasta Onamı: Yazııı hasta onamı bu çalışmaya katılan hastadan alınmıştır.

Hakem Değerlendirmesi: Dış bağımsız.

Çıkar Çatışması: Bu çalışmada herhangi bir çıkar çatışması bulunmamaktadır.

Finansal Destek: Bu çalışmada herhangi bir finansal destek alınmamıştır.

Informed Consent: Written informed consent was obtained from the patient who participated in this study.

Peer-review: Externally peer-reviewed.

Conflict of Interest: The author declared no conflict of interest.

Financial Disclosure: The author declared that this study has received no financial support.

\section{Kaynaklar}

1. Dejerine J, Roussy G: Le syndrome thalamique. Rev Neurol 1906; 14 521-32.

2. Bogousslavsky J, Van Melle G, Regli F: The Lausanne Stroke Registry: analysis of 1,000 consecutive patients with first stroke. Stroke 1988; 19 : 1083-92. [CrossRef]

3. Bogousslavsky J, Regli F, Uske A. Thalamic infarcts: clinical syndromes, etiology, and prognosis. Neurology 1988; 38: 837-48. [CrossRef]

4. Matheus MG, Castillo M. Imaging of acute bilateral paramedian thalamic and mesencephalic infarcts. AJNR Am J Neuroradiol 2003; 24: 2005-8.

5. Kumral E, Evyapan D, Balkır K, Kutluhan S. Bilateral thalamic infarction: Clinical, etiological and MRI correlates. Acta Neurol Scand 2001; 103 : 35-42. [CrossRef]

6. Khoiny A, Goldberg M, Khoiny N. Presentation with good outcome in a bilateral paramedian thalamic infarction. Journal of Neurological Sciences (Turkish) 2006; 23; 54-8.

7. Schmahmann JD. Vascular syndromes of the thalamus. Stroke 2003; 34 2264-78. [CrossRef]

8. Şenol MG, Göbel M, Özdağ F, Saraçoğlu M. Bilateral Talamik Infarkt: Dört Olgunun Analizi. Türk Serebrovasküler Hastalıklar Dergisi 2008; 14: 53-6.

9. Bakar M. Post Stroke Demans (Epidemiyoloji ve Risk Faktörleri). Demans Dergisi 2003; 1: 15-20.

10. Krolak-Salmon P, Croisile B, Houzard C, Setiey A, Girard-Madoux P, Vighetto A. Total recovery after bilateral paramedian thalamic infarct. Eur Neurol 2000; 44: 216-8. [CrossRef] 